\title{
Commentary
}

\section{Can Studies of Aluminum Toxicity In Vivo and In Vitro Provide Relevant Information on the Pathogenesis and Etiology of Alzheimer's Disease?}

\author{
John Savory ${ }^{\mathrm{a}, *}$ and Othman Ghribi ${ }^{\mathrm{b}}$ \\ ${ }^{a}$ Department of Pathology, University of Virginia, Charlottesville, VA, USA \\ ${ }^{\mathrm{b}}$ Department of Pharmacology, Physiology and Therapeutics, University of North Dakota School of Medicine, \\ Grand Forks, ND, USA
}

The study reported in the present issue of the Journal of Alzheimer's disease by Mizoroki et al. [8] concludes that the failure of treatment of transgenic mice with aluminum maltolate to induce Alzheimer's-like neuropathological changes provides proof that aluminum is not a causative agent in the etiology of Alzheimer's disease. In our opinion, this report by Mizoroki et al. fails to provide an incisive analysis of previous work on the possible role of aluminum as an initiator of neurodegeneration, both in experimental animals and in humans. Dietary aluminum has been shown to increase brain amyloidosis in APP transgenic mice [11]. Since neurofibrillary tangles and neuritic plaques appear to be seen in only a few animal species, including aged bears [1] and, of course, humans, it is not surprising that aluminum compounds in most species fails to reproduce the neuropathological and biochemical abnormalities seen in Alzheimer's disease. Such a lack of an exact match in abnormal features does not rule out

* Corresponding author: John Savory, P.O. Box 800214, Department of Pathology, University of Virginia Health Sciences Center, Charlottesville, VA, USA. Tel.: +1 434924 5682; Fax: +1 434924 2574. this metal ion as a contributing factor in the etiology of Alzheimer's disease.

Aluminum should certainly be high on the list of such possible candidates. Firstly, it is highly abundant in the environment, being the most abundant metal in the Earth's crust. Secondly, it is extremely neurotoxic once it gains access to the central nervous system. Its proven toxicity in dialysis encephalopathy attests to this neurotoxicity, as do many experimental animal studies including several from our own laboratory (see for review [13]). Mizoroki et al. should not expect mice to exhibit brain lesions exhibiting neurofibrillary pathology upon exposure to aluminum since mice and rats, for some reason, appear to be relatively resistant to the induction of such lesions by aluminum. Rabbits are much more sensitive to aluminum compounds, particularly if the route of administration is directly into the central nervous system, as shown initially by Klatzo et al. [4]. Studies using rabbits may be particularly relevant to the investigation of human disease since, according to an impressive 88 protein sequences, they belong to the mammalian order Lagomorpha, a group which has been reported more closely to resemble primates than rodents [3]. 
Most of our own work on this topic has used a similar animal model system and we have demonstrated, as cited by Mizoroki et al., that the intracisternal injection of aluminum maltolate into New Zealand white rabbits will induce abundant neurofilamentous aggregates which contain hyperphosphorylated tau, ubiquitin, $\alpha 1$-antichymotrypsin, and phosphorylated and non-phosphorylated neurofilament protein, as well as demonstrating evidence of oxidative stress and apoptosis. All of these features are seen in the Alzheimer's disease brain. Although such findings do not prove that aluminum causes this disorder, it does show that once this neurotoxic metal ion gains access to the brain, it can induce some of the neuropathological and abnormal biochemical changes found in Alzheimer's disease. Coupled with such findings in our laboratory and others is the strong evidence that aluminum accumulates in the neurofibrillary tangles of Alzheimer's disease patients [5,9].

There are a myriad of other considerations in this "aluminum/Alzheimer's disease" hypothesis that are beyond the scope of this commentary but have been reviewed by us in detail [13]. In addition, there are many other recent publications on the subject $[2,7,10]$. Factors such as the lack of an increased incidence of Alzheimer's disease in individuals ingesting large quantities of aluminum-containing antacids, and the question of the inconsistent presence of neurofibrillary tangles in the brain of dialysis encephalopathy caused by hyperaluminemia are just two of such considerations. However, animal experiments of aluminum-induced neurodegeneration provide supporting evidence that aluminum can induce some of the Alzheimer's-like changes. The question as to whether aluminum does cause or contribute to Alzheimer's disease remains unanswered, but should still be a consideration in light of several positive findings in the laboratory (for a review see [12], and by epidemiological studies [6]. In view of the vast effort in finding a cause for Alzheimer's disease focusing on many experimental models and other approaches, there is still little progress in finding a cause. Aluminum accumulation in the brain of elderly affected individuals should not be discarded as a possible major, or perhaps minor, contributor.

\section{References}

[1] L.C. Cork, R.E. Powers, D.J. Selkoe, P. Davies, J.J. Geyer and D.L. Price, Neurofibrillary tangles and senile plaques in aged bears, J Neuropathol Exp Neurol 47 (1988), 629-641.

[2] J.L. Domingo, Aluminum and other metals in Alzheimer's disease: a review of potential therapy with chelating agents, $J$ Alzheimers Dis 10 (2006), 331-341.

[3] D. Graur, L. Duret and M. Gouy, Phylogenetic position of the order Lagomorpha (rabbits, hares and allies), Nature 379 (1996), 333-335.

[4] I. Klatzo, H. Wisniewski and E. Streicher, Experimental Production of Neurofibrillary Degeneration. I. Light Microscopic Observations, J Neuropathol Exp Neurol 24 (1965), 187-199.

[5] M.A. Lovell, W.D. Ehmann and W.R. Markesbery, Laser microprobe analysis of brain aluminum in Alzheimer's disease, Ann Neurol 33 (1993), 36-42.

[6] D.R. McLachlan, C. Bergeron, J.E. Smith, D. Boomer and S.L. Rifat, Risk for neuropathologically confirmed Alzheimer's disease and residual aluminum in municipal drinking water employing weighted residential histories, Neurology 46 (1996), 401-405.

[7] A.C. Miu and O. Benga, Aluminum and Alzheimer's disease: a new look, J Alzheimers Dis 10 (2006), 179-201.

[8] T. Mizoroki, S. Meshitsuka, S. Maeda, M. Murayama, N. Sahara and A. Takashima, Aluminum induces tau aggregation in vitro but not in vivo, J Alzheimers Dis 11 (2007), in press.

[9] D.P. Perl and A.R. Brody, Alzheimer's disease: X-ray spectrometric evidence of aluminum accumulation in neurofibrillary tangle-bearing neurons, Science 208 (1980), 297-299.

[10] D.P. Perl and S. Moalem, Aluminum and Alzheimer's disease, a personal perspective after 25 years, J Alzheimers Dis 9 (2006), 291-300.

[11] D. Pratico, K. Uryu, S. Sung, S. Tang, J.Q. Trojanowski and V.M. Lee, Aluminum modulates brain amyloidosis through oxidative stress in APP transgenic mice, FASEB J 16 (2002), 1138-1140.

[12] J. Savory, O. Ghribi and M.M. Herman, Aluminum, in: Heavy Metal in the Environment, B. Sarkar, ed., Marcel Dekker, New York, 2002, pp. 309-348.

[13] J. Savory, M.M. Herman and O. Ghribi, Mechanisms of aluminum-induced neurodegeneration in animals: Implications for Alzheimer's disease, J Alzheimers Dis 10 (2006), $135-144$. 